\title{
Pengaruh Kualitas Pelayanan Terhadap Loyalitas Konsumen Di Hotel Best Western Plus Kemayoran, Jakarta
}

\author{
Dadang Kurnia Abdurrahman ${ }^{1 a_{*},}$ Sri Fajar Ayuningsih ${ }^{2 b}$ \\ ${ }^{a}$ Prodi Hospitaliti dan Pariwisata - Institut STIAMI Jakarta \\ ${ }^{\mathrm{b}}$ Prodi Bisnis Perhotelan - Universitas Agung Podomoro Jakarta \\ ${ }^{1}$ dadangkurnia457@gmail.com, ${ }^{2}$ sri.ayuningsih@ podomorouniversity.ac.id \\ *corresponding author
}

ARTICLE INFO

Article history

Received

Revised

Accepted

Keywords

Service Quality

Customer Loyality

Hotel

\begin{abstract}
This study aimed to analyze the effect of service on customer loyalty at the Best Western Plus Hotel Kemayoran. The research method used is a quantitative research approach. Data collection techniques to test hypotheses through a questionnaire addressed to 50 respondents who use the services of the Best Westen Plus Hotel Kemayoran. And equipped with making observations and literature study. The respondent sample data collection was carried out using an accidental sampling technique. The data analysis method used consists of validity test, reliability test, standard linear analysis test with $t$ test, product moment correlation coefficient, and determination coefficient. The results obtained from the analysis of SPSS statistical data processing and hypothesis testing, namely the correlation coefficient between the service quality variable $(X)$ and the customer loyalty variable $(Y)$ is significant because it is between $0.5<r<075$. Based on the results of the t-test analysis, the results are greater than the table, namely 2.604> 2.01. This figure shows that $\mathrm{HO}$ is rejected and $\mathrm{HI}$ is accepted, which means that the service quality variable $(X)$ has a significant effect on customer loyalty $(Y)$.
\end{abstract}

\section{Pendahuluan}

\subsection{Latar Belakang}

Saat ini, sektor pariwisata menjadi modal strategis dalam membantu meningkatkan perekonomian nasional sebagai salah satu sumber penerimaan devisa negara. Beberapa sektor pariwisata yang mengalami pertumbuhan akan memicu sektor lain untuk berkembang dan memberikan dampak ganda, di antaranya terhadap sektor pertanian, peternakan, perkebunan, dan kerajinan tangan. Hal ini juga dapat menimbulkan dampak positif, khususnya pada peningkatan kesempatan kerja, peningkatan pendapatan, dan peningkatan kesejahteraan masyarakat.

Strategi pengembangan kawasan daerah tujuan wisata juga perlu dilakukan. Salah satunya ialah dengan menyediakan kebutuhan wisatawan yaitu amenitas. Amenities adalah fasilitas-fasilitas pendukung di kawasan wisata berupa ketersediaan sarana akomodasi yang memadai, di antaranya termasuk hotel.

Hotel Best Western Plus Kemayoran merupakan salah satu sarana pariwisata yang menyediakan fasilitas dan pelayanan penginapan, ruang rapat, makan dan minum, serta jasa lain yang dikelola secara komersial. Berlokasi di Jalan Benyamin Suaeb Blok A5, Kemayoran, merupakan hotel bintang empat yang dikelola oleh PT. Global Pertama Sejahtera, dan sudah beroperasi selama 
ini memiliki 156 kamar dan berada di lingkungan bisnis yang strategis, yaitu berdekatan dengan JIEXPO (Jakarta International Expo), sebuah area konvensi dan pameran terbesar di Indonesia.

Untuk menjaga loyalitas konsumen, Hotel Best Western Plus Kemayoran memiliki kualitas staf yang unggul dan berusaha memberikan kualitas pelayanan terbaik. Namun demikian, konsumen akan membandingkan layanan yang diberikan Hotel Best Western Plus Kemayoran dengan ekspektasi layanan sesuai keinginan konsumen.

Jika konsumen merasa puas, maka mereka akan kembali menggunakan jasa perusahaan dan menjadi setia, serta akan menceritakan pengalaman tersebut kepada konsumen lain. Sehingga, perusahaan akan mendapatkan keuntungan dari kondisi tersebut, yaitu mendapatkan konsumen yang loyal sekaligus dengan senang hari bersedia membantu promosi secara word of mouth atau dari mulut ke mulut.

Begitu pula jika konsumen merasa tidak puas, maka pengalaman yang mengecewakan tersebut akan diceritakan kepada konsumen lain. Jika, tidak diantisipasi dengan baik oleh manajemen, maka hal ini dapat memperburuk citra dan eksistensi Hotel Best Western Plus Kemayoran. Pada akhirnya, hal ini dapat berdampak pada penurunan jumlah konsumen.

Berdasarkan latar belakang masalah tersebut, penulis tertarik mengadakan penelitian terhadap Hotel Best Western Plus Kemayoran dengan judul "Pengaruh Kualitas Pelayanan terhadap Loyalitas Konsumen di Hotel Best Western Plus Kemayoran."

\subsection{Hotel dan Jasa}

Jakarta, sebagai ibukota negara Indonesia menjadi pintu masuk utama bagi kedatangan wisatawan. Kunjungan wisatawan, baik domestik maupun mancanegara, dengan tujuan untuk berlibur ataupun alasan bisnis, tentunya membutuhkan tempat menginap. Salah satu usaha jasa yang menyediakan fasilitas menginap adalah hotel.

Menurut Bagyono (2014), hotel adalah jenis akomodasi yang dikelola secara komersial dan profesional yang menyediakan jasa pelayanan penginapan, makan dan minum, serta pelayanan lainnya bagi tamu yang datang.

Sementara, yang dimaksud dengan jasa ialah setiap tindakan atau perbuatan yang ditawarkan oleh suatu pihak yang bersifat tidak berwujud fisik dan tidak menghasilkan kepemilikan atas sesuatu (Tjiptono, 2014), serta dihasilkan dan dikonsumsi secara bersamaan, juga memberikan nilai tambah bagi konsumen (Zethaml dan Bitner dalam Lupiyoadi, 2013).

\subsection{Kualitas Pelayanan}

Menilai mutu suatu jasa atau produk tak jauh berbeda dengan menilai kepuasan konsumen. Penilaian ini ditentukan dengan menggunakan variabel harapan dan variabel kinerja yang dirasakan. Agar jasa atau produk dapat dikelola dengan baik dan berkualitas, maka manajemen sebuah bisnis atau perusahaan perlu mencermati lima kesenjangan penyebab kegagalan perusahaan.

Lima kesenjangan atau gap tersebut di antaranya ialah, (1) gap antara harapan atau keinginan konsumen dan persepsi pengelola usaha; (2) gap antara persepsi pengelola usaha dan spesifikasi kualitas jasa atau produk; (3) gap antara spesifikasi kualitas jasa atau produk dan cara penyampaiannya; (4) gap antara penyampaian jasa atau produk dan komunikasi eksternal; (5) gap antara jasa atau produk yang dirasakan dan yang diharapkan (Tjiptono (2011).

\subsection{Dimensi Kualitas Pelayanan}

Menurut Parasuraman dan kawan-kawan yang dikutip dalam buku Manajemen Jasa karangan Fandy Tjiptono (2004) menyatakan, kualitas layanan merupakan suatu konsep yang terdiri dari lima 
- Reliability (Kehandalan), yaitu kemampuan memberikan pelayanan yang dijanjikan dengan segera, akurat, dan memuaskan.

- Assurance (Jaminan/Kepastian), mencakup pengetahuan, kemampuan, kesopanan, dan sifat dapat dipercaya yang dimiliki para staf. Dengan kata lain, anggota perusahaan harus tampil lebih kompeten, memiliki pengetahuan dan keahlian di bidang masing-masing. Dimensi ini terdiri dari empat aspek, yaitu competency, courtesy, credibility, dan security.

- Empathy (Empati), yaitu memberikan perhatian tulus dan bersifat pribadi yang diberikan kepada para konsumen. Menurut Parasuraman, terdapat tiga hal penting pada dimensi ini, yaitu accessibility, communication skill, understanding the costumer, tangibles, dan responsiveness.

\subsection{Loyalitas Konsumen}

Loyalitas konsumen dapat dipresentasikan dalam pembelian yang konsisten terhadap produk atau jasa dalam jangka panjang. Bahkan, bagi konsumen yang loyal, mereka bersedia merekomendasikan produk atau jasa tersebut kepada orang lain.

Faktor-faktor yang mempengaruhi loyalitas konsumen di antaranya ialah nilai (harga dan kualitas), citra, kenyamanan dan kemudahan dalam mendapatkan produk atau jasa, kepuasan, pelayanan, garansi dan jaminan (Marconi dalam Doyo, 2006). Menurut Dharmmesta (1999) dalam Nurullaili (2013), menjelaskan bahwa faktor-faktor yang menentukan loyalitas konsumen, meliputi faktor harga, pelayanan, kualitas, dan promosi.

\section{Metode Penelitian}

Penelitian ini menggunakan pendekatan penelitian kuantitatif, di mana kualitas pelayanan sebagai variabel $\mathrm{X}$ dan loyalitas konsumen sebagai variabel $\mathrm{Y}$. Penelitian ini dilakukan untuk membuktikan bahwa terdapat hubungan antara pengaruh kualitas pelayanan terhadap loyalitas konsumen di Hotel Best Western Plus Kemayoran di Jakarta. Hipotesis penelitian ini adalah:
$\mathrm{H} 0=$ Tidak terdapat pengaruh antara kualitas pelayanan terhadap loyalitas konsumen Hotel Best Western Plus Kemayoran.
H1 = Terdapat pengaruh antara kualitas pelayanan terhadap loyalitas konsumen Hotel Best Western Plus Kemayoran.

\begin{tabular}{|c|c|}
\hline KUALITAS PELAYANAN & LOYALITAS KONSUMEN \\
\hline Reability & Nilai \\
\hline Responsiveness & Citra \\
\hline Assurance & Kenyamanan \\
\hline Empathy & Kepuasan \\
\hline Tangible & Harga \\
\hline Tiiptono 2004 \& 2011 & $\begin{array}{l}\text { Marconni dalam Doyo (2006) dan } \\
\text { Dharmmesta dalam Nurullaili } \\
\text { (2013) }\end{array}$ \\
\hline
\end{tabular}

\section{Gambar 2.1. Kerangka Teori}

Dalam penelitian ini, sumber data yang digunakan adalah data primer yang didapat langsung dari responden yang mengisi kuesioner. Populasi responden adalah konsumen Hotel Best Western Plus Kemayoran pada periode Juni 2019 dengan total populasi sebanyak 2.863 konsumen.

Merunut pada pendapat Roscoe yang dikutip oleh Uma Sekaran (2006) memberikan acuan umum untuk menentukan ukuran sampel, yaitu ukuran sampel lebih dari 30 dan kurang dari 300 
adalah tepat untuk kebanyakan penelitian. Berdasarkan pendapat tersebut, maka jumlah jumlah sampel yang ditetapkan dalam penelitian ini adalah sebanyak 50 responden.

Teknik yang digunakan untuk mengukur data kuesioner yaitu dengan Skala Likert. Rentang nilai atau pembobotan yang digunakan untuk mengukur indikator variabel dalam penelitian ini adalah skala 1 (satu) sampai 5 (lima). Tingkat pembobotan skala Likert untuk indikator variabel kualitas pelayanan dan loyalitas konsumen dapat dilihat pada Tabel 1.

Tabel 2.1 Skala Pengukuran Likert

\begin{tabular}{|c|c|c|}
\hline No. & Keterangan & Bobot/Nilai \\
\hline 1 & Sangat Tidak Setuju (STS) & 1 \\
\hline 2 & Tidak Setuju (TS) & 2 \\
\hline 3 & Kurang Setuju (KS) & 3 \\
\hline 4 & Setuju (S) & 4 \\
\hline 5 & Sangat Setuju (SS) & 5 \\
\hline
\end{tabular}

Selanjutnya, hasil pembobotan kuesioner akan ditafsirkan atau diinterpretasikan menggunakan skala interval dengan kriteria interval sebesar 0,80. Dari ketentuan tersebut, maka kriteria penilaian adalah seperti yang tampak pada Tabel 2.

Tabel 2.2. Skala Pengukuran Interval Kategori

\begin{tabular}{|c|c|c|}
\hline No. & Keterangan & Bobot/Nilai \\
\hline 1 & Sangat Baik & $4,21-5,00$ \\
\hline 2 & Baik & $3,41-4,20$ \\
\hline 3 & Cukup Baik & $2,61-3,40$ \\
\hline 4 & Kurang Baik & $1,81-2,60$ \\
\hline 5 & Sangat Tidak Baik & $1,00-1,80$ \\
\hline
\end{tabular}

Sedangkan, data sekunder penelitian diperoleh dari hasil penelusuran data penelitian terdahulu, studi pustaka atau kajian literatur, jurnal, dan situs web yang berkaitan dengan permasalahan yang sedang diteliti. Lalu, pada tahap selanjutnya data yang diperoleh akan diolah kembali untuk mendukung pembahasan penelitian ini.

\section{Hasil dan Pembahasan}

Awalnya, Best Western Plus Kemayoran didirikan tanggal 1 Desember 2013 dengan nama Best Western Grand Palace Kemayoran. Satu tahun kemudian, namanya diganti menjadi Best Wetern Kemayoran, sebab telah memenuhi standar Best Western Internasional. Selanjutnya, pada tahun 2016 Best Western Kemayoran berganti nama menjadi Best Western Plus Kemayoran, karena mendapat predikat nilai tertinggi se-Asia Pasifik.

Berdasarkan hasil olah data kuesioner dari 50 responden, berikut adalah rekapitulasi penilaian variabel 
Tabel 3.1. Rekapitulasi Variabel Kualitas Pelayanan

\begin{tabular}{|l|c|c|}
\hline \multicolumn{1}{|c|}{ Indikator } & $\begin{array}{c}\text { Nilai } \\
\text { Rata-rata }\end{array}$ & Kriteria \\
\hline 1. Karyawan memberikan pelayanan dengan cepat & 4,12 & Baik \\
\hline $\begin{array}{l}\text { 2. Karyawan dapat memberikan solusi mengenai masalah } \\
\text { yang dihadapi }\end{array}$ & 4,04 & Baik \\
\hline $\begin{array}{l}\text { 3. Karyawan memiliki pengetahuan, kemampuan, kesopanan, } \\
\text { dan dapat dipercaya }\end{array}$ & 4,12 & Baik \\
\hline $\begin{array}{l}\text { 4. Karyawan memberikan jaminan kepuasan pelayanan } \\
\text { sesuai ekspektasi konsumen }\end{array}$ & 4,06 & Baik \\
\hline $\begin{array}{l}\text { 5. Karyawan mampu memahami setiap kebutuhan } \\
\text { konsumennya }\end{array}$ & 3,92 & Baik \\
\hline $\begin{array}{l}\text { 6. Karyawan memberikan perhatian dalam mendengarkan } \\
\text { keluhan konsumen }\end{array}$ & 4,16 & Baik \\
\hline 7. Fasilitas kolam renang nyaman & 4,02 & Baik \\
\hline 8. Fasilitas restoran yang nyaman & 4,10 & Baik \\
\hline $\begin{array}{l}\text { 9. Karyawan yang memberikan informasi kepada konsumen } \\
\text { secara tepat dan lengkap }\end{array}$ & 4,06 & Baik \\
\hline $\begin{array}{l}\text { 10. Karyawan bersifat responsif terhadap keperluan } \\
\text { konsumen }\end{array}$ & 4,16 & Baik \\
\hline Ratata & Baik & \\
\hline
\end{tabular}

Dari Tabel 3.1 di atas, secara umum dapat dijelaskan bahwa seluruh indikator dinilai Baik. Dengan nilai tertinggi diperoleh oleh dua indikator, yaitu karyawan memberikan perhatian dalam mendengarkan keluhan konsumen dan karyawan bersifat responsif terhadap keperluan konsumen, dengan nilai sebesar 4,16. Sementara, nilai terendah diperoleh indikator karyawan mampu memahami setiap kebutuhan konsumennya, dengan nilai sebesar 3.98. Tetapi, dengan angka ratarata interpretasi untuk variabel kualitas pelayanan sebesar 4,07 dan angka tersebut termasuk dalam skala 3.41 - 4.20 dengan kriteria penilaian Baik.

Sementara, hasil rekapitulasi penilaian variabel loyalitas konsumen adalah sebagai berikut.

Tabel 3.2. Rekapitulasi Variabel Kualitas Pelayanan

\begin{tabular}{|l|c|c|}
\hline \multicolumn{1}{|c|}{ Indikator } & $\begin{array}{c}\text { Nilai } \\
\text { Rata-rata }\end{array}$ & Kriteria \\
\hline $\begin{array}{l}\text { 1. Konsumen dapat memberikan nilai lebih untuk hotel Best } \\
\text { Western Plus Kemayoran dibandingkan dengan hotel bintang } \\
\text { 4 pada umumnya }\end{array}$ & 3,78 & Baik \\
\hline $\begin{array}{l}\text { 2. Konsumen tidak merasa kecewa dengan harga dan kualitas } \\
\text { yang diberikan }\end{array}$ & 3,82 & Baik \\
\hline $\begin{array}{l}\text { 3. Citra yang dimiliki membuat konsumen tidak beralih ke } \\
\text { hotel lain }\end{array}$ & 3,74 & Baik \\
\hline $\begin{array}{l}\text { 4. Citra yang dimiliki lekat dengan mengutamakan kepuasan } \\
\text { dan kenyamanan konsumen }\end{array}$ & 3,92 & Baik \\
\hline $\begin{array}{l}\text { 5. Konsumen merasa aman menginap di Hotel Best Western } \\
\text { Plus Kemayoran Hotel }\end{array}$ & 3,98 & \\
\hline
\end{tabular}




\begin{tabular}{|l|c|c|}
\hline $\begin{array}{l}\text { 6. Konsumen merasa nyaman menginap di Hotel Best } \\
\text { Western Plus Kemayoran }\end{array}$ & 3,90 & Baik \\
\hline $\begin{array}{l}\text { 7. Konsumen merasa puas dilayani oleh karyawan Hotel Best } \\
\text { Western Plus Kemayoran }\end{array}$ & 4,04 & Baik \\
\hline $\begin{array}{l}\text { 8. Konsumen merasa puas dengan fasilitas yang diberikan } \\
\text { Hotel Best Western Plus Kemayoran }\end{array}$ & 3,98 & Baik \\
\hline $\begin{array}{l}\text { 9. Konsumen merasa harga yang diberikan sesuai dengan } \\
\text { hotel bintang 4 pada umumnya }\end{array}$ & 3,98 & Baik \\
\hline $\begin{array}{l}\text { 10. Konsumen merasa harga yang diberikan sesuai dengan } \\
\text { pelayanan yang diberikan }\end{array}$ & 4,02 & Baik \\
\hline \multicolumn{1}{|c|}{ Rata-rata } & $\mathbf{3 , 9 1}$ & \\
\hline
\end{tabular}

Dari Tabel 3.2 di atas, dapat diinterpretasikan bahwa seluruh indikator dinilai Baik. Dengan nilai tertinggi diperoleh oleh indikator yaitu konsumen merasa puas dilayani oleh karyawan Hotel Best Western Plus Kemayoran, dengan nilai sebesar 4,04. Sementara, nilai terendah diperoleh indikator citra yang dimiliki hotel Best Western Plus Kemayoran membuat konsumen tidak beralih ke hotel lain, dengan nilai sebesar 3.74. Tetapi, dengan angka rata-rata interpretasi untuk variabel loyalitas konsumen sebesar 3,91 dan angka tersebut termasuk dalam skala $3.41-4.20$ dengan kriteria penilaian Baik.

Sehingga berdasarkan Tabel 4 dan Tabel 5, dapat diartikan secara rata-rata bahwa kualitas pelayanan dan loyalitas konsumen hotel Best Western Plus Kemayoran dinilai Baik.

Hasil perhitungan koefisiensi determinasi variabel kualitas pelayanan yang mempengaruhi variabel loyalitas konsumen di Hotel Best Western Plus Kemayoran sebesar 60,1\%. Dengan hasil perhitungan koefisien determinasi ini diketahui bahwa besarnya pengaruh kualitas pelayanan terhadap loyalitas konsumen di Hotel Best Western Plus Kemayoran sebesar 60,01\%, sedangkan faktor lain sebesar 39,9\% .

Pengujian hipotesis menunjukan bahwa $\mathrm{H} 0$ ditolak $\mathrm{H} 1$ diterima, karena hasil $\mathrm{t}$ hitung $>\mathrm{t}$ tabel $(2,604>2,01)$. Artinya, terdapat pengaruh positif dan signifikan antara kualitas pelayanan terhadap loyalitas konsumen di Hotel Best Western Plus Kemayoran.

\section{Kesimpulan dan Saran}

\subsection{Kesimpulan}

Berdasarkan hasil penelitian dan pembahasan mengenai pengaruh kualitas pelayanan terhadap loyalitas konsumen di Hotel Best Western Plus Kemayoran, maka dapat disimpulkan bahwa kualitas pelayanannya dapat dikatakan baik. Tingkat loyalitas konsumen di Hotel Best Western Plus kemayoran juga dinilai baik. Pengaruh kualitas pelayanan terhadap loyalitas konsumen di Hotel Best Western Plus Kemayoran dapat dikatakan sangat kuat dan berpengaruh secara signifikan. Dengan hasil tersebut, maka dapat disimpulkan bahwa H0 ditolak dan H1 diterima.

\subsection{Saran}

Berdasarkan uraian kesimpulan di atas, maka disarankan kepada manajemen Hotel Best Western Plus Kemayoran agar mampu menjaga loyalitas konsumen dengan cara memahami setiap kebutuhan konsumennya dan meningkatkan kualitas pelayanan. Sebab, pada aspek tersebut nilainya relatif rendah atau di bawah nilai rata-rata 


\section{Referensi}

Bagyono. 2014. Pariwisata dan Perhotelan. Bandung: Alfabeta.

Doyo, P. (1998). Perilaku Konsumen dan Loyalitas. Penerbit Andi, Yogyakarta

Lupiyoadi, Rambat. 2014. Manajemen Pemasaran Jasa. Edisi 3. Jakarta: Salemba Empat.

Nurullaili. 2013. Analisis Faktor-Faktor Yang Memengaruhi Loyalitas Konsumen Tupperware (Studi pada Konsumen Tupperware di Universitas Diponegoro). Jurnal Volume 2, Nomor 1, Maret 2013.

Roscoe, 1975, dikutip dari Uma Sekaran, 2006, Metode Penelitian Bisnis, Salemba Empat, Jakarta.

Tjiptono, Fandy. 2004. Manajemen Jasa, Edisi Pertama, Yogyakarta: Penerbit Andi. 103

Tjiptono, Fandy. 2011. Service Management Mewujudkan Layanan Prima. Edisi 2. Yogyakarta: Andi.

Tjiptono, Fandy. 2014. Pemasaran Jasa. Yogyakarta: Penerbit Andi.

\section{Sumber internet :}

bwpluskemayoran.com diakses pada tanggal 8 April 2019 